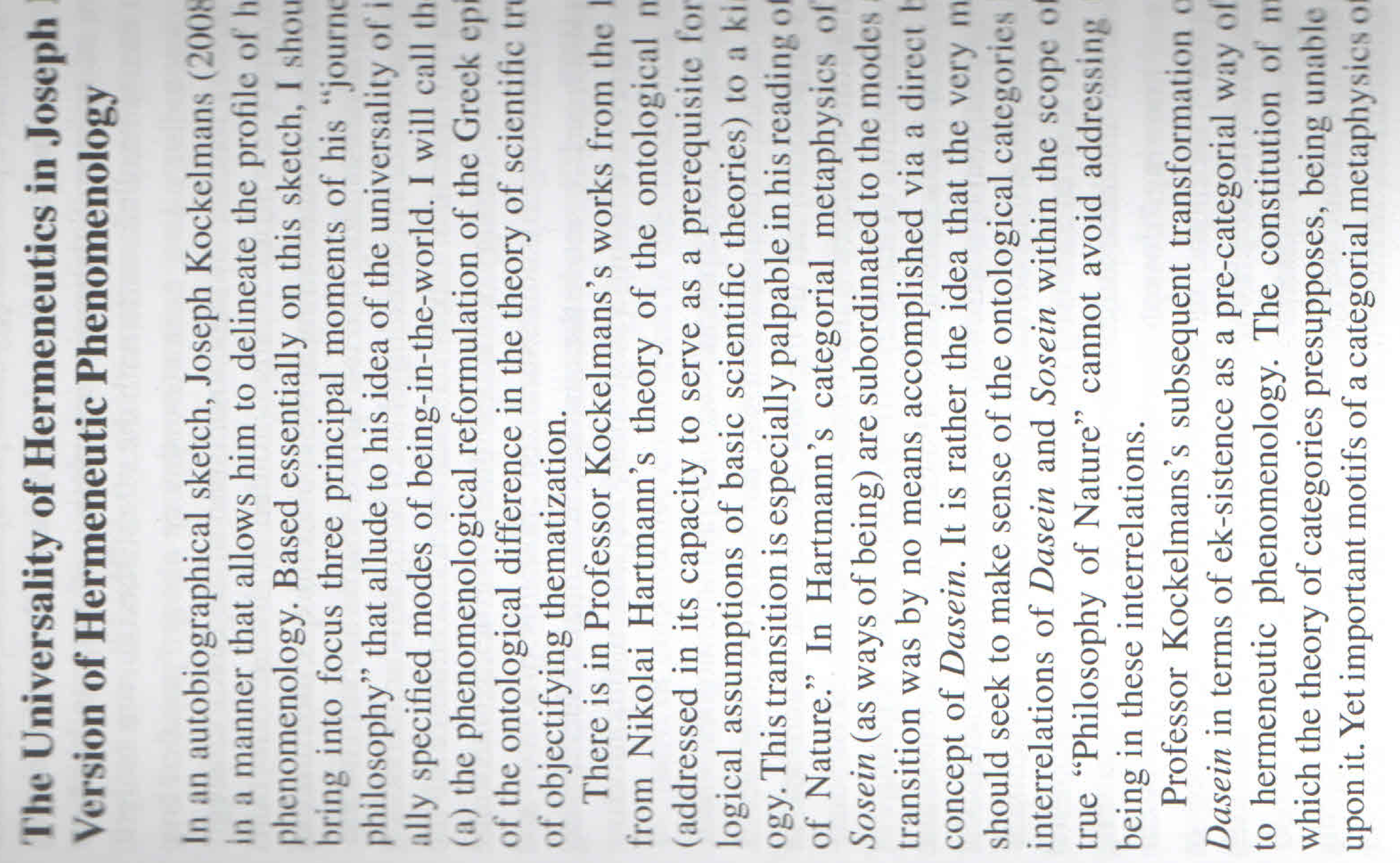

施
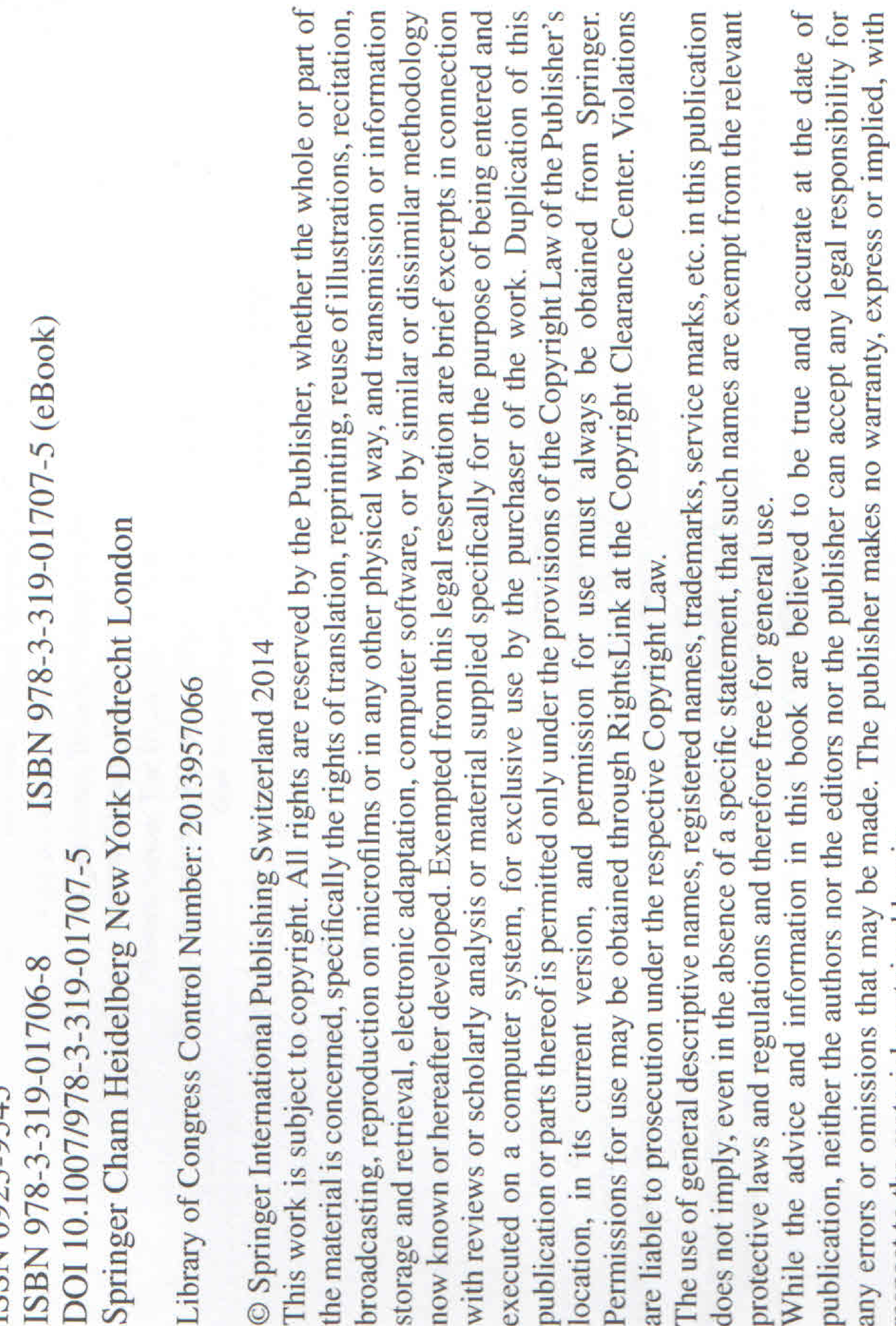

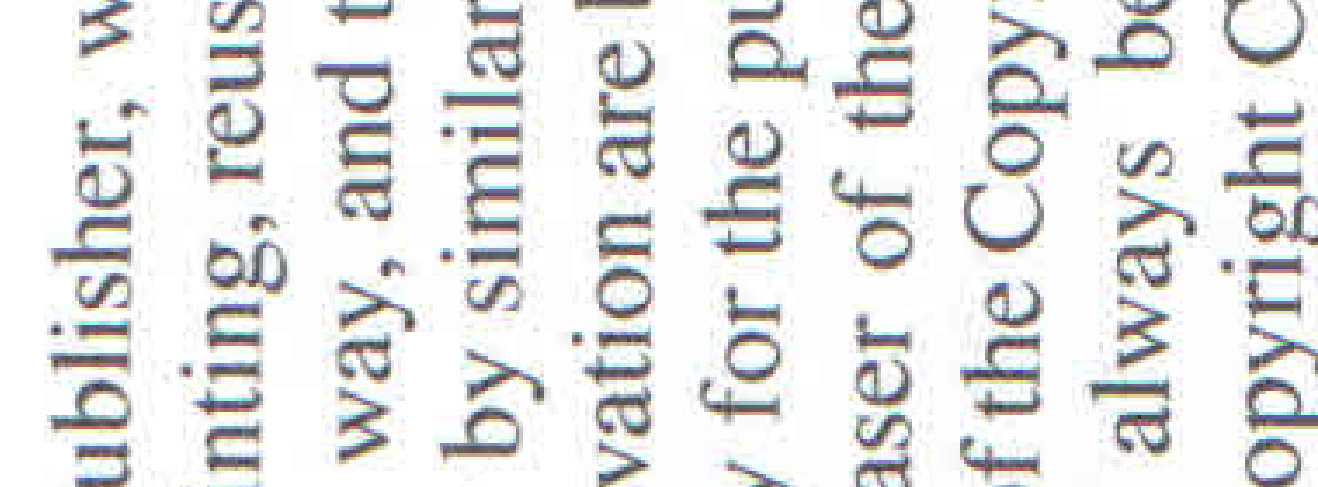

视 要

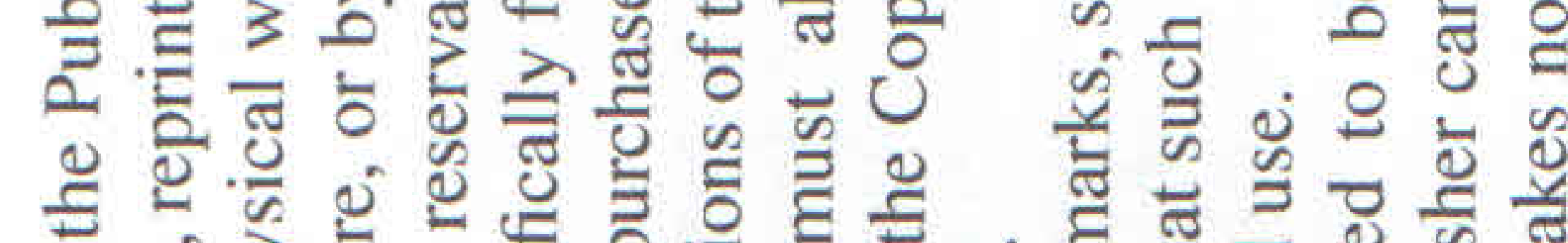

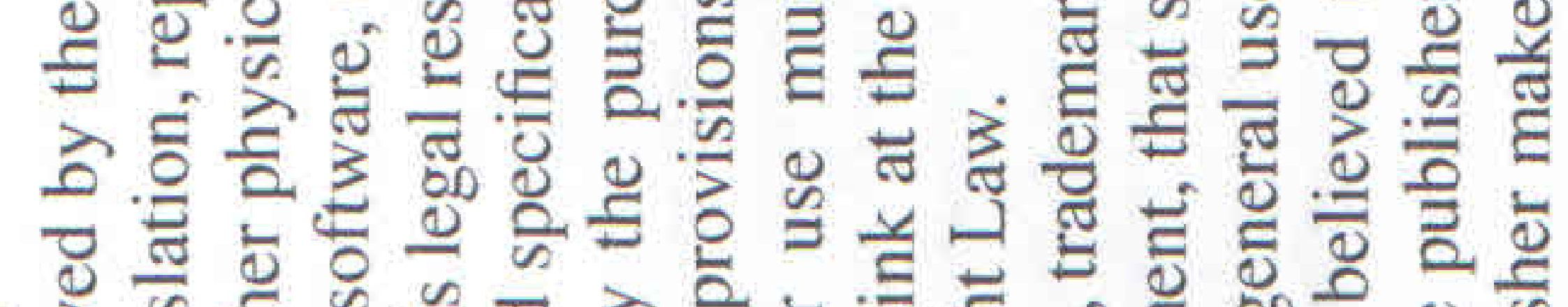

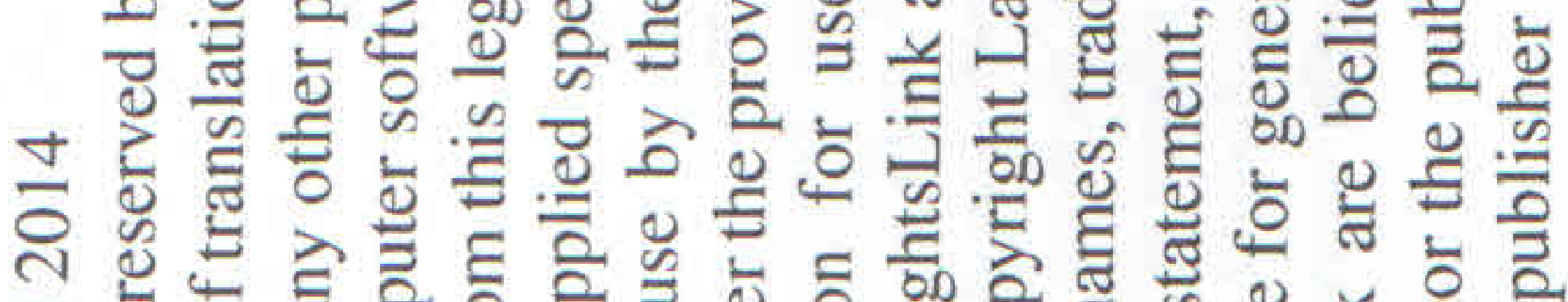

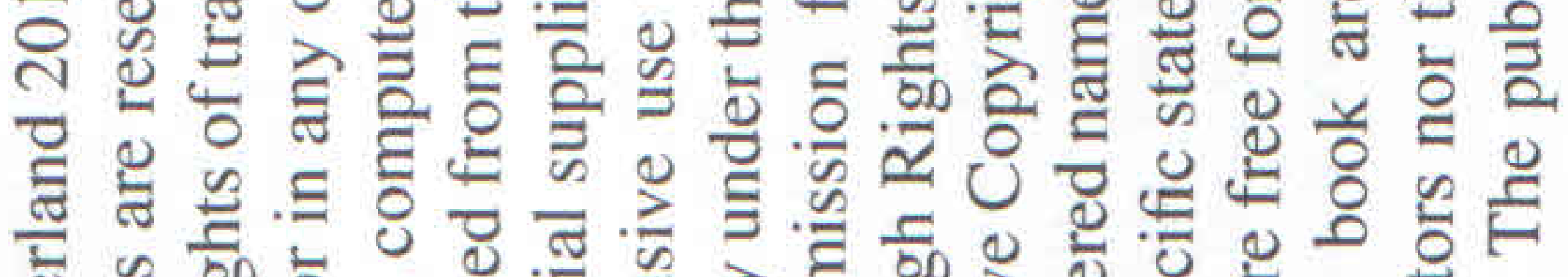

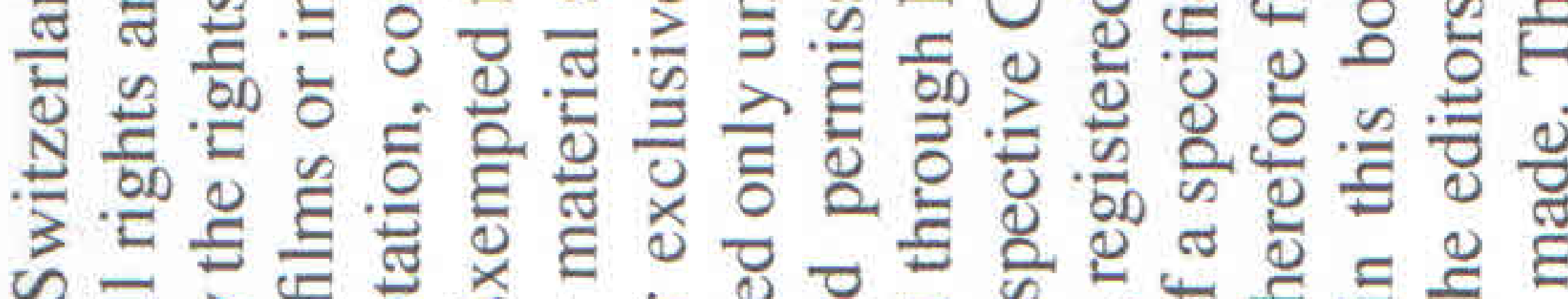

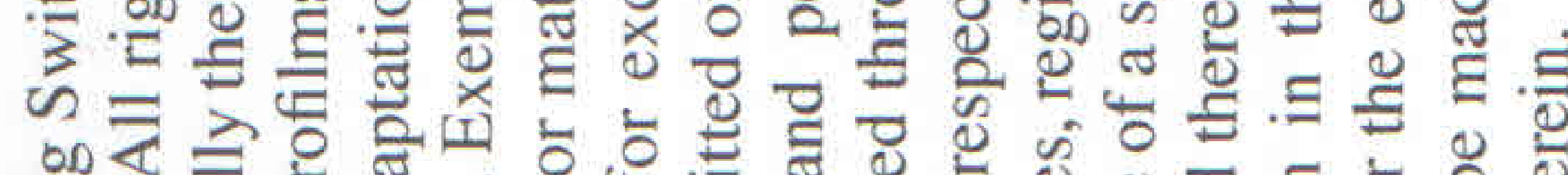

3

$\infty$ ํํㅁ

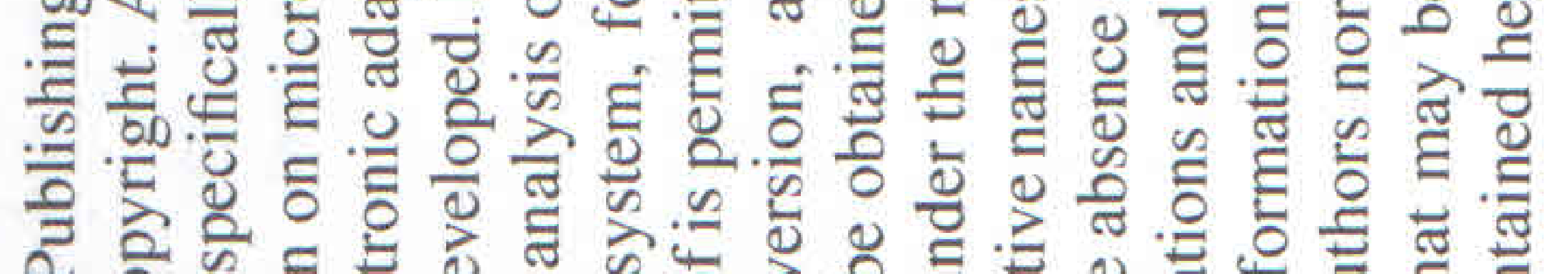

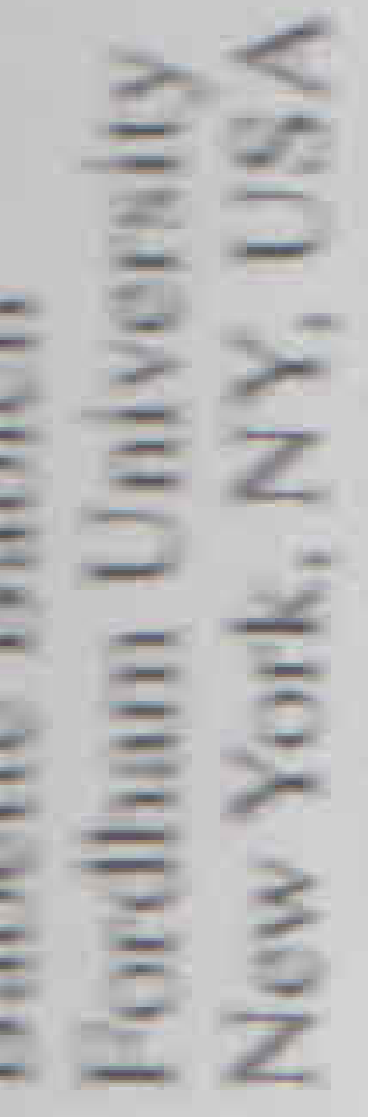

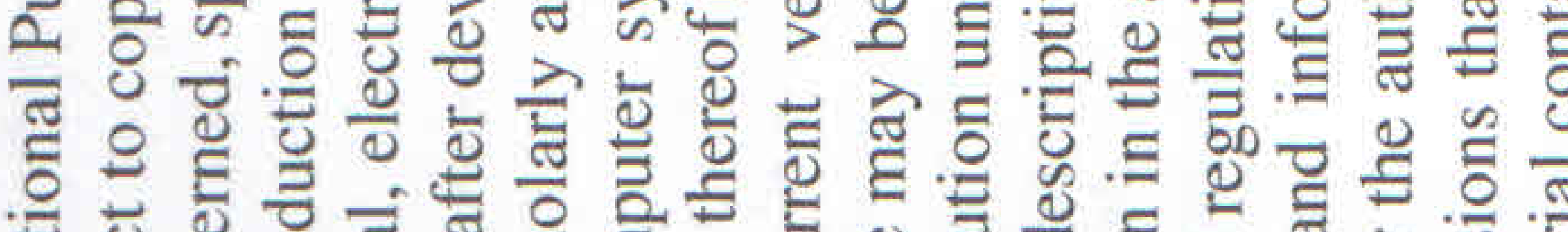

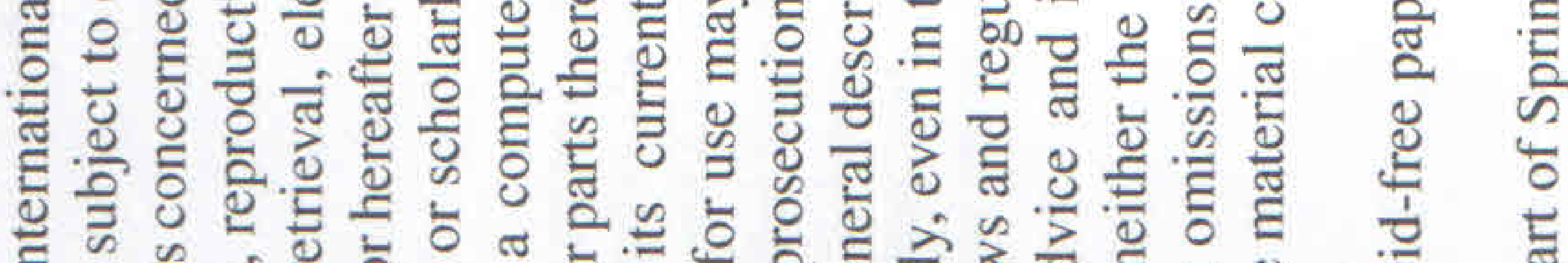

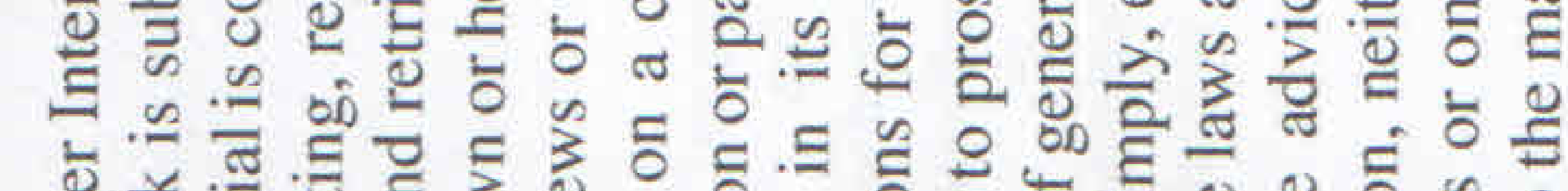

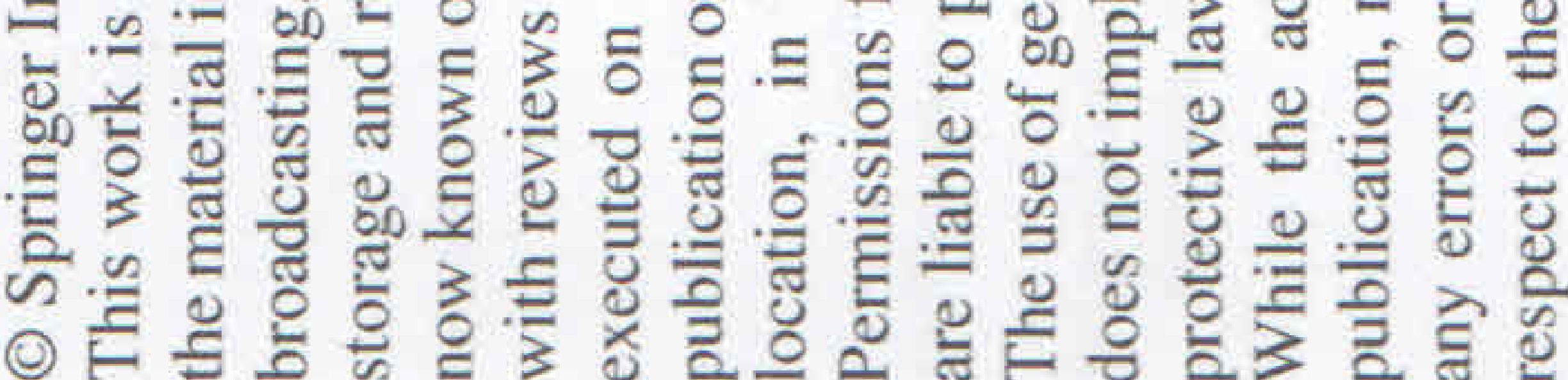

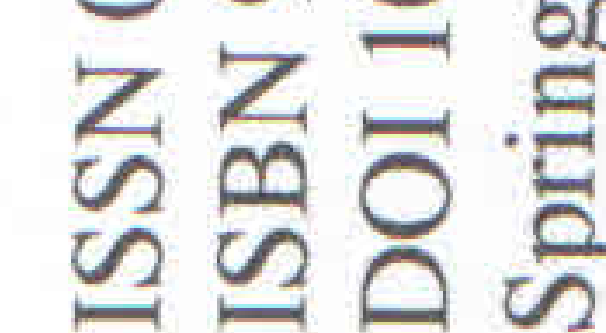




\title{
The Infinite Science of the Lifeworld: Steps Toward a Postfoundational Phenomenology
}

\author{
Giovanni Leghissa
}

\begin{abstract}
This essay considers the problem of historicity together with the paradoxes of foundation. The concept of lifeworld has been studied mainly in order to clarify two orders of problems, the first concerning the relationship between history and the lifeworld, the second concerning the paradoxes contained in the Krisis regarding the possibility to attain a new foundation of transcendental phenomenology. Both issues must be taken into consideration before we question the possibility of a science of the lifeworld.
\end{abstract}

\section{The Problem of Historicity and the Paradoxes of Foundation}

The concept of lifeworld has been studied mainly in order to clarify two orders of problems, the first concerning the relationship between history and the lifeworld, the second concerning the paradoxes contained in the Krisis regarding the possibility to attain a new foundation of transcendental phenomenology. Both issues must be taken into consideration before we question the possibility of a science of the lifeworld.

On the one hand, starting from Ricoeur's and Landgrebe's pioneering essays, ${ }^{1}$ much attention has been paid to the problem of historicity. The aim was not to show how Husserl, a philosopher with strong interests in mathematics, succeeded in structuring a coherent philosophy of history at the end of his career, after decades

\footnotetext{
${ }^{1}$ Ricoeur (1949), Landgrebe (1963, 1968, 1982).

G. Leghissa ( $\square)$

Dipartimento di Filosofia e Scienza dell'educazione, University of Turin,

Via Sant'Ottavio, 20, Torino 10124, Italy

e-mail: giovanni.leghissa@unito.it 
spent in a deep and, to a certain extent, ambiguous dialog with Dilthey's historicism. ${ }^{2}$ Much more interesting was the explanation of the strategies adopted by Husserl in developing a transcendental historicity, which can be seen as a consequence-and a deepening — of some aspects of Husserl's philosophy developed during the Twenties, that is, time consciousness, passive synthesis and intersubjectivity. It could be disappointing not to find in the late Husserl's philosophy a fulfilled project culminating in a philosophy of history, the scope of which should be the unfolding of all the intentional ties binding together human knowledge of the world and human self-positioning in the world itself. Nevertheless, we must be content with the result accomplished by Husserl-and with the well grounded supposition that this result was precisely what Husserl himself aimed at: the theory of the lifeworld has not been conceived to found a new concept of historicity, it is rather the tool needed by phenomenology in order to achieve a solid point of departure that makes a phenomenologically oriented reflection on both the natural and the scientific attitude possible. ${ }^{3}$ (I will return to this point later).

On the other hand, it is the paradoxical structure that characterizes Husserl's path towards transcendental phenomenology that has drawn much attention. This paradoxical structure seems to be no obstacle, but rather a rhetoric necessity within the argument set out in the Krisis; more precisely, it seems to be intrinsically related to the impossibility of maintaining a distinction between the transcendental and the empirical subject (Hua VI 1954, 182-185). ${ }^{4}$ What we discover after having accomplished the reduction, is nothing but the interweaving of ourselves and the general structure of the world, the latter considered as the sedimentation [Sedimentierung] of the never-ending human activity of sensemaking. Surely, according to what constitutes the main achievement of Husserl's philosophy since the Prolegomena, all sensemaking relies on logical structures, the validity of which does not depend on their being accomplished within a singular act of judgement. However, the kind of intentional analysis developed by phenomenology makes it necessary to make evident not only how their instantiation-for example within a singular act of judgement - constitutes the condition of possibility for the world to be known by any subject whatsoever, but also how the subject itself plays a role in constituting the way in which pieces of the world appear in time. The analysis of constitution shows that it is not possible to consider the constituting subject as if it were an external moment of the process of constitution itself. The phenomenological domain described by the term subjectivity is the result of a peculiar way of looking at the process of constitution, thanks to which we can point out the role played by the subject; but, as a result of the phenomenological analysis, what reveals itself to be peculiar to the domain described this way is the fact that the subject which constitutes the objects that appear in the flow of consciousness and confers them with identity and stability, at the same time constitutes itself and its own persistence as an identical pole of the subjective processes.

\footnotetext{
${ }^{2}$ Ströker (1987), 160-186.

${ }^{3}$ Carr (1974), Ströker (1987), 139-159.

${ }^{4}$ Ströker (1987), 115-138.
} 
From this interconnection of constituting and being constituted stems the fact that it becomes more and more difficult to maintain the purity that should characterize the transcendental sphere of the ego-which is another way to articulate the aforementioned difficulty of maintaining the distinction between the transcendental and the empirical. This state of affairs becomes more evident as soon as we consider that the ego envisaged by phenomenological analysis is not simply the individual self, but rather a pole belonging to a more extended intentional process. This extension encompasses not only the intentional life of an individual consciousness, but also everything that links this individual consciousness to previous acts of constitution, accomplished by other subjects. Every present intentional act of mine is surrounded by a living horizon within which a complex set of relationships is still operating, and precisely these relationships form the context outside which no individual belief could be meaningful: every singular belief is thus interwoven not only with my past experience, but also with a wider texture of beliefs constituting the shared meaning of the world (Hua VI 1954, 152, 169). Therefore, the whole generative intersubjectivity, meant as the alternation of human generations within the course of history, cannot be detached from the idiosyncratic styles of perceiving and conceiving the world that are peculiar to each subject (Hua XI 1966, 218f).

In stressing the importance of the intersubjective structure of the lifeworld, Husserl underlines the fact that there is no access to any shared and common experience without our being affected bodily by other subjects: the mere presence of others, their actual being here, within my own Umwelt, or their having been present as a member of a historical community I still belong to, constitute the founding moment of any actual experience. In this way, phenomenology extends the reach of its own analysis to fields where the boundary of the egological sphere reveals not the mark of a closure, but rather what allows exteriority to affect the inner structure of the subject. Intersubjectivity, otherness, corporeality build up together a unit of themes the articulation of which shows how much dimension we could qualify as anthropological matters for the self-fashioning of the transcendental sphere. ${ }^{5}$

Thus, both Husserl and his interpreters have to cope with the uncomfortable paradox contained in the fact that the subject, called-or, better, summoned-to guarantee for the validity of every act of constitution, depends for its own constitution on what belongs to a sphere of exteriority affected by a relentless contingency. The efforts made by Husserl to sidestep this difficulty could be interpreted as the expression of the desire to save both the transcendental role played by the subject and the awareness that it is impossible to bestow on the transcendental ego the properties required by the agent supposed to guarantee for what classical philosophy called Letztbegründung. Regardless of Husserl's own intentions, one could say that phenomenology has simply substituted any form of Letztbegründung with the infinite operativity (Fungierung) of intersubjective life, or, which amounts to the same, with the uninterrupted work of constitution carried out by the human community. If one wants, on the contrary, to take into account the intentions that

\footnotetext{
${ }^{5}$ Zahavi (2003), 79-140, stresses the importance of the connection between time, corporeality, and
} intersubjectivity in order to understand the meaning of the life-world. 
animated the Husserlian project, the main effort should consist in clarifying the reason why a philosophical account of reality should have its point of departure in the subject, as it is the case within the phenomenological version of the transcendental argument, and why precisely the argumentative structure of such an account marks the difference between phenomenology and other forms of discourse claiming for their part to shape through linguistic categories a persuasive description of human being in the world.

However, what is at stake here is not a defence of Husserl's attempts to maintain the 'purity' of the transcendental sphere. Much more important is the question concerning the benefit we can obtain in accepting the transformation that the transcendental stance undergoes within the Krisis. And, again, the way we deal with this transformation is important not to measure our fidelity to the Husserlian project of a transcendental phenomenology, but to give us the possibility of saving the epistemic goal pursued by phenomenology even in absence of a transcendental foundation.

This sounds like a strong claim and therefore requires a more extensive explanation. As we have seen, no matter whether we take into consideration the problem of history, or the question of what is needed to accomplish a transcendental foundation, we encounter the following questions: is it still possible to speak of a foundation if the transcendental subjectivity that should sustain the burden of it coincides with the process of constitution itself? Are we forced to see in the Husserlian solution nothing but a doomed attempt to elude the fact that the transcendental domain coincides with the domain of history - a domain affected by an irreducible finiteness? An answer should not be attempted too hastily. There are good reasons, in fact, for questioning any attempt to let phenomenology flow into hermeneutics too quickly, which would be precisely the result of an assumption that transcendentality and historicity coincide. Even if we feel uncomfortable with the term 'transcendental,' we must recognize that the rhetorical function it exerts cannot be renounced too easily: the transcendental stance is plainly the philosophical stance meant as the possibility of a critical attitude towards reality, as the uninterrupted work of questioning every realm of the world with no reference to an agency supposed to transcend the world itself. In Husserlian terms, it is the attitude we attain whenever we keep the world at a distance in order to reflect on our being engaged in the world, or, better, on our being engaged in that given network of relationships that make possible the validity of the common knowledge of the world (Hua VI 1954, 153).

Furthermore, forcing Husserl's late philosophy into any form of historicism yields little benefit in philosophical terms. The battle fought by Husserl against any form of psychologism - with historicism as one of its forms-belongs to the perennial effort made by philosophy to state that concepts like 'truth,' not to mention the concept of 'concept,' are not parts of a whole called 'nature,' or the 'empirical world' if you prefer. It could be more appropriate, then, to find the solution for the questions posed above precisely in turning the paradox into an epistemic resource. ${ }^{6}$ As we shall see, what is aimed at in this way is not the validation of Husserl's efforts

${ }^{6}$ Even if with different aims, a similar solution has been suggested in Dodd (2004). 
to safeguard the transcendental character of phenomenology at any rate. Much more important is the yield obtained by investing in a philosophical project the generative element of which allows for the renouncing of any foundational stance. ${ }^{7}$ Postfoundationalism means here not only to assume that phenomenology achieves its significance as a philosophical project only through its capability of establishing only the conditions of possibility of validity, and by far not the conditions of possibility of experience; it also means that the possibility of a transcendental questioning depends on historical factors, an exhaustive analysis of which is, in principle, impossible. The coincidence between empirical and transcendental ego seen by Husserl as the paradox of transcendental phenomenology could be thus interpreted as the clue of the fact that a transcendental questioning remains a possibility, which each subject can always put into operation, yet without being able to justify the necessity of accomplishing it.

Truly, there is no phenomenological self-positioning in the world if the subject avoids carrying out the epoché, as it can be stated, for example, by looking at the sense of the controversy between Husserl and Heidegger during the late Twenties. In other words, a theoretical necessity, deeply rooted in the phenomenological mode of thought, brings Husserl to establish the epoché as the doorway to phenomenology. But this necessity, I argue, is largely rhetorical in nature and related to the difficulties phenomenology meets when it has to articulate, at the argumentative level, its own paradoxical position. As Husserl himself states, carrying out the epoché is an exercise (Hua VI 1954, 140; Hua VII 1959a, 279f; Hua VIII 1959b, 11f), a praxis which can not be justified only in theoretical terms; or, better, it is a performance carried out by a subject that was not otherwise able to manage its own position as a transcendental agent in the awareness that this position does not mean exteriority with respect to experience. Considered this way, the epoché loses its foundational character, but it maintains its role within a transcendental argument, the core of which is to be displaced differently from the traditional way of understanding it, that is, it is to be repeated and re-shaped as a figure of speech which performs the accomplishment of that stance which we can at best define through the adjective 'critical.'

The core of the argument I am putting forth here consists of the aforementioned fact that the position of the subject exercising the critique cannot be considered as the point of departure that allows access to an absolute exteriority. On the one hand, Husserl's phenomenology pursued as its deepest aim the destruction of any form of ingenuous realism, that is, of the idea that reality can be approached with immediacy-or, if we prefer to say the same in more poetic terms, phenomenology could be seen as the rebellion against the tyranny of the sense data. According to Husserl, this tyranny must be fought principally in the name of a methodological clarification of what informs the scientific construction of reality. On the other hand, the decision to bring scientific constructs back to the lifeworld in order to show that they depend

\footnotetext{
${ }^{7}$ Even if oriented towards issues that differ from the one discussed here, the question of a postfoundational attitude within the phenomenological project is also raised and discussed in Mensch (2001) and Drummond (1990).
} 
on intersubjectivity is not motivated by the goal to substitute scientific realism with that form of realism which accompanies our ordinary experience of the world. The latter, in fact, knows its own way to conceal the role played by intersubjectivity as a presupposition for any human sensemaking, and therefore is not structurally different from the scientific attitude, if we look at both from the perspective of phenomenology. The problem is that the phenomenologist finds herself in a position that is rooted in the field of intesubjectivity as well: a position that allows looking at the processes of constitution from outside this field simply does not exist. This is the reason why critique pursued by phenomenology finds its ultimate motivation in an 'existential' choice, of which it is not possible to give an account thoroughly articulated in purely conceptual terms (Hua VI 1954, 60).

Along with the path just traced, where we suggested that the relationship between transcendentality and historicity should be interpreted as the starting point for the articulation of a postfoundational position, it becomes possible to put the question concerning the science of the lifeworld on a basis that should reach beyond the impasses met by Husserl. If we are not afraid of considering the coincidence between transcendental and empirical as the normal status of the phenomenological investigation whenever the question of foundation is at stake, and, furthermore, if we are ready to accept that anthropology is the final destiny of phenomenology, then to put in practice a science of the lifeworld should not mean to describe the structures of a realm the existence of which is needed to establish the system of all that exists; it could rather mean to describe the possibility of invariants within given forms of experiencing the world. In this sense, I will argue-and this constitutes the main goal of the present essay - that the place the humanities occupy within the encyclopaedia is the only possible site where we can find the accomplishment of a science of the lifeworld.

\section{Positing the Lifeworld, or How to Supplement the Transcendental Position}

In order to pursue this aim, it should be shown what characteristics could be attributed to the lifeworld. The first thing to be kept in mind is that the lifeworld is not a place you can go through, you can inhabit, or where you can smell aromas or touch objects. It is not the world of everyday life.$^{8}$ Of the latter it is possible to have a descriptive science, able to provide us with the main tools needed to build up a theory of social action. A theory of social action, to put it briefly, has to explain why human groups, or communities, act in a particular way under circumstances that are given each time. Of course, a social theory which does not confine itself to a simple collection of case studies can provide good—or bad—explanations for the reason why a motivation is not precisely a form of causation, that is, it can frame

\footnotetext{
${ }^{8}$ Grathoff (1989), 91-121.
} 
its own conceptuality in such a way that it is possible to distinguish the realm of human actions from the realm of natural events. Nevertheless, a social theory is not forced to give any account of the constitutive operations that led to its own establishment. In other words, there is no need for it to practice a second order reflection on its own tools and operations. If this is the case, we are looking at a social theory that reveals an influence either by Husserlian phenomenology, ${ }^{9}$ or by another philosophical stream. ${ }^{10}$ Precisely the absence of such a second order reflection makes a given social theory not very different from a natural science, which is characterized, according to Husserl, by the claim of being able to account for the deep structure of reality without exposing the subjective operations that brought about the shaping of its own theoretical edifice. What the phenomenologist wants to provide, instead, is a theory of intersubjectivity, the function of which is to explain how the social construction of reality works-including that peculiar form of social construction we usually call 'scientific knowledge.' The point here is that Husserl needs to create a 'place' (a 'stage,' I would even say) where the intersubjective construction of reality is made evident—is made visible in absolute purity. Without stressing this 'purity,' Husserl would hardly be able to attribute a transcendental character to intersubjectivity itself. This is also the reason why Husserl emphasizes so much the evident character of the objects met in the lifeworld-an emphasis which renders the lifeworld a 'place' where ordinary events use to happen almost regularly, where we expect to meet a given set of objects and not others. In other words, in the lifeworld we are expected to encounter all the possible objects, whereas it is the inner legality governing this totality that determines the way we encounter them (Hua VI 1954, 142f).

No need to say that the lifeworld is a 'world' where even the philosopher would be out of place. ${ }^{11}$ Philosophy is a very peculiar form of sensemaking, universal in its forms of expression. "Wonder" [thaumazein] was the name given by Greek philosophers to the attitude enabling us to question the mere 'givenness' of things, in order to grasp what makes the world to be what it is. A similar will to look at the things we find in the world without trusting the immediacy that characterizes tour experience and knowledge of them is surely to be found among all human cultural traditions. This ubiquity of the philosophical gaze at the world must be stressed in order to correct the conviction, expressed by Husserl, according to which philosophy is strictly tied with the cultural development of the Western cultural tradition. But, apart from any concern for the relationship between philosophy and the cultural context in which it arises, what must be put in evidence now is the fact that philosophy gives expression to the desire both to investigate the intimate nature of things, and to explore the possibility that things could be different from what they are. Strictly related to that desire is the awareness, which increases through methodical observation, that we cannot exclude the possibility that, sometimes,

\footnotetext{
${ }^{9}$ Luhmann as well as Bourdieu are the authors that could be mentioned in the present context (see in particular Bourdieu 1977 and Luhmann 1995).

${ }^{10}$ For example: Winch (1958) and Bloor (1976).

${ }^{11}$ Blumenberg (2010).
} 
there could be a discrepancy between perception and belief, or between how we represent the world and how the world effectively is. In other words, it is peculiar to what we call philosophy to pose the question of truth. Further refined, this question gives rise to complex forms of knowledge, thanks to which, if properly institutionalized, it becomes possible not only to establish some statements supposed to be true about reality, but also to justify why they should be held for true. Yet if the lifeworld is the place where evidence characterizes the encounter with every object that can be found in it, then the philosophical questioning about the condition of possibility of truth remains pointless.

In the lifeworld the philosopher would know exactly what grounds those harmonious experiences that she, like any other human being, must presuppose in order to cope with any possible alteration of validity. Within our usual intercourse with objects it can occur-and in fact occurs - that harmony disappears and our experience ceases to be harmonious; both thanks to the corrections I can make, and thanks to communalization of what is perceivable, that is, thanks to the fact that the world I perceive is the same world that is perceived by others, whose communication of what they perceive completes what I perceive, it is always possible to re-establish a harmonious experience. But such a common understanding of the world, such a communalization reached through the uninterrupted re-agreement between what I perceive and what is, or has been perceived by others, is possible only because I 'know' that other human beings are related to same world: both the individual subject and others have a common horizon which encompasses the totality of all possible things to be met in the course of experience (Hua VI 1954, 167). What Husserl points at by describing the transcendental character of this horizon, is the fact that it operates as a presupposition within each form of human intercourse. Without having signed any contract, an agreement is always possible as regards the concordance of what is perceived within the world. This concordance (or 'harmony,' the English translation for Einstimmigkeit) is precisely the result of the awareness that the horizon is always operating as a presupposition held to be present both by myself and by others. But it would be misleading to think that this concordance, once achieved, coincides with the lifeworld; the lifeworld itself is to be found rather on the side of the horizon. In this sense, the lifeworld names the total system of multiplicities that makes possible the unity of human experience of the same world. This unity can even be missed on occasion, but what counts is the possibility of it-a possibility that, according to Husserl, accompanies every single act of perception. In itself, however, the horizon cannot become an object we can grasp or perceive (Hua VI 1954, 145f). ${ }^{12}$ What can be perceived intuitively is, rather, the legal character of it, that is, the fact that the structure of the lifeworld is subject to the same inner logic found in every system of multiplicity.

However, if we state that the lifeworld is no place for philosophers, because within its realm there is no need for any philosophical investigation about the reason why the harmony of our experience can sometimes fail, what brought Husserl to establish the necessity of the life-world? Why did he choose to introduce

\footnotetext{
${ }^{12}$ Held (1991).
} 
this concept? The answer is well known and sounds quite naive: because he needed a new point of departure for phenomenology. According to Husserl, this point of departure must maintain the purity that is proper to any realm supposed to play a transcendental role. Nevertheless, there is something that induces us to think that the lifeworld is more or less a phenomenologist's invention: both the average man and the scientist keep on living in the world and experiencing the world without any knowledge of the fact that their living in the world or experiencing it presupposes the lifeworld. Put like this, it does not sound as serious as it should. Yet, the invention I am talking about must meet the requirements that characterize the conceptual objects philosophers are used to dealing with. In fact, without the positioning (in the strong sense of Setzung) of the lifeworld, there would be nothing to justify the peculiar self-positioning of the philosopher in front of both the natural and the scientific attitude. ${ }^{13}$ In this sense, I argue, the lifeworld is supposed to be the proxy of that transcendental position that should exist if the philosopher could hold it. We can at best explain this argument by turning it into the question about the origin of the lifeworld. At a first glance, the lifeworld, being the horizon of our experience, has no origin for its own. Not very differently from what happens with the law of logic investigated first in the Prolegomena, and then in Formale und transzendentale Logik, what we envisage when we meet the lifeworld is an object the property of which is to exist without any reference to space-time: omnitemporality [Allzeitlichkeit] is the expression used by Husserl to describe the way of existence peculiar to such logical entities. Nevertheless, Husserl did not withdraw from the task of phenomenologically investigating the fact that even logical forms and laws can be analysed in relation to their being intentioned by a subject. Precisely this investigation marked the gap between his position and Frege's from the beginning of their philosophical contention. ${ }^{14}$ Furthermore, it is a radicalisation of Husserl's displacement of what defines the logical form within a theory of intentional consciousness that led him to add the genetic method to the previous static one. Thus, it is no surprise that the thematisation of the lifeworld, which made its appearance in correlation with the establishment of the genetic method, has been carried out by Husserl in such a way that the question about the origin of the lifeworld is far from being irrelevant.

But how can the lifeworld be originated on its part if its function is precisely to make every form of origination possible? It is important not to forget that the lifeworld is the result of a two-fold reduction accomplished in relation both to the natural attitude and to the scientific attitude..$^{15}$ Within the social exchange that characterizes our every day life, we meet other people and objects, or we deal with institutions; in none of these circumstances are we aware of the fact that every form

\footnotetext{
${ }^{13}$ Ströker (1987, p. 87f).

${ }^{14}$ Mohanty (1982), Willard (1984).

${ }^{15}$ What follows is an oversimplification, in the sense that I won't account for the steps necessary to pass from the epoché of the natural attitude to the reduction of the scientific one to the evidences we can seize in the life-world. For a more detailed account, see Dodd (2004), 175-206. As far as the peculiarity of the reduction of the scientific attitude is concerned, see also Kisiel (1970).
} 
of human relationship, every meaningful experience of the external world, as well as every commitment we met to the various forms of sociability, formally or informally institutionalised, stems from our being involved in a broader web of intersubjective relationships (Hua VI 1954, 149). Precisely these relationships make it possible for our multifaceted exchange with the world to maintain a constant meaning. But they remain constantly concealed: we keep on acting individually as if we were detached from the broader context made up by intersubjectivity, a context that frames all our individual action. As far as the concealment of this universal frame is concerned, not far more different is the situation that characterizes the scientific attitude. ${ }^{16}$ In the case we decide to investigate the world from a scientific perspective, we can then attain a comprehensive knowledge of the world from which we would be precluded if we were still involved in the natural attitude. ${ }^{17}$ But each member of the scientific community works on her own research program, closely with other colleagues, without questioning the operations needed to attain scientific knowledge itself. In Husserl's terms, the scientific interest that motivates each member of the scientific community is such as to induce a forgiveness of the intersubjective operations that brought both to the establishment of science, meant as a peculiar way of approaching reality, and to the construction of singular scientific theories or doctrines, meant as given instantiation of what science is (Hua VI $1954,134) .{ }^{18}$ In order to establish the visibility of those intentional ties that connect both our every day experience of the world and the systematic knowledge of the world furnished by science to the web of intersubjective relations, it is thus necessary, according to Husserl, to perform the phenomenological reduction-or, better, a twofold one: the first in order to bracket the natural attitude, the second in order to disconnect the scientific one. As a consequence, the lifeworld is what remains, is what we can see operating as system of intersubjective relations presupposed both by the natural and by the scientific attitude. What must be stressed in the present context is the fact that the subject performing the reduction can only be the phenomenologically oriented philosopher, with 'philosopher' not referring to a particularly gifted person: the philosopher in question is simply someone who shares the same word in its facticity with others, and can, on occasion, decide to investigate the world scientifically, but presently makes up her mind to perform the reduction in order to disclose the operativity [Fungierung] of intersubjectivity. Truly, we have to do here with an individual position, which, in principle, everybody can partake in-

\footnotetext{
${ }^{16}$ Held (1991) has made the point very clear by defining the scientific attitude as a second-level natural attitude.

${ }^{17}$ As stated by several passages from his work, Husserl nor put in doubt the achievements of scientific knowledge, neither was willing to disrupt the idea that scientific knowledge is the only one giving us the possibility to access the 'true' world. Whether the Husserlian conception of the relationship between scientific knowledge and truth can still be maintained, is an issue we cannot address here. On the subject, see Hacking (1992).

${ }^{18}$ Fleck (1979) and Bourdieu (2001) not only move in the same direction as Husserl, but also show how productive a phenomenologically oriented sociology of knowledge could be; nevertheless, these contributions still find scarce recognition within Anglo-Saxon sociology of knowledge (even if Fleck's work was issued in 1935).
} 
and such a possibility guarantees for the fact that this position maintains affinity with the universality supposed to characterize the transcendental subjectivity. But this affinity cannot efface the irreducible contingency affecting the position of the subject that wants to perform the reduction.

Thus, it seems to be justified to claim that the lifeworld is a sort of 'invention' by phenomenologists in order to make the phenomenological stance possible. The latter reveals to be one possibility, one among others, of looking at the world; other attitudes, which are motivated by other interests, can underlie different ways of looking at the world, which, of course, still remains the same world we all have in common as human beings. As a consequence, the contingent character of the motivation that underlies the phenomenological attitude thoroughly affects the structure of the lifeworld as well: if taken as the result of a peculiar way of looking at the role played by intersubjectivity in order to better understand how the uninterrupted work of sensemaking come to existence, the lifeworld seems to be nothing but the result of the individually chosen positional act that produces its visibility. What stems from this contingency is that the lifeworld is to be understood more as an archive of some invariant patterns than as the totality encompassing all what exists within human experience. If the lifeworld is the place where these invariants are to be found, and if phenomenology is to be the science of the lifeworld, we must now identify the peculiarities of the phenomenological inquiry with respect to other disciplines that claim, on their part, to be better appointed to carry out the same inquiry.

\section{The Encyclopaedia of the Humanities as Infinite Description of the Lifeworld}

As a result of the previous analysis, what we want to achieve now is the possibility of a science of the lifeworld that coincides with the definition of the anthropological bases needed to understand the most general pattern of human behaviour. This science could claim to be still understood as 'philosophy' because of the fact that it coincides neither with the natural nor with the scientific attitude. What it loses, nevertheless, is the adjective 'transcendental,' of which Husserl is so fond. Hans Blumenberg has spent a lot of philosophical energy showing that the obsession with the purity that should characterise the phenomenological discourse prevented Husserl from allowing phenomenology to turn itself into a philosophical anthropology. ${ }^{19}$ If phenomenology remains a transcendental discourse, than purity is safeguarded. However, this does not offer a great advantage: a 'pure' science of the lifeworld seems to have a limited descriptive power; as Husserl knew, in fact, psychology (as well as history) can offer better accounts of how human beings act in the world. Furthermore, a 'pure' science of the lifeworld seems to have a limited prescriptive power as well: as we have already pointed out above, both the scientist

\footnotetext{
${ }^{19}$ Blumenberg (2006).
} 
and the human beings who find their way about in the world by taking advantage from that shared knowledge we call 'common sense' are not aware of the evidence that informs the lifeworld, and nevertheless they keep on doing what they do seemingly very well (whereas 'very well' means 'in an adaptive manner,' or 'in a satisfying manner from an adaptive point of view'). The result of Blumenberg's analysis is that renouncing a transcendental stance is a benefit, and not a loss-a benefit I would describe as an injection of anthropological flesh into the skeleton of the lifeworld.

We cannot follow the whole argument made by Blumenberg in order to demonstrate both why Husserl was not able to accept an anthropological stance, and why an anthropological turn within phenomenology could be seen as an improvement; nevertheless, one point should not be overlooked, and this point can be seen as a development of Blumenberg's whole argument. The reason why phenomenology needs to be turned into anthropology, which obviously has as a result the loss of transcendentality, is tightly related with the transcendental stance itself. If the transcendental subject reflects upon its own self-positioning, and takes into account the finiteness that marks its position, the consequence that must be drawn is that the subject, precisely for transcendental reasons, is subdued to this finiteness, or, to put it differently, that the subject must ascribe to its own finiteness a transcendental character. The finiteness we are dealing with here is not a metaphorical designation for our being mortal, it is rather the main property of our being related to the network of the intentionally structured sensemaking processes that constitute the common world and are all together called 'intersubjectivity' by the phenomenologist: the subject can access this network only through a given number of entrances, each of which, in part, is shaped in conformity with the social and communicative competences achieved by the subject itself. Thus, this finiteness is the condition of possibility of our being in the world. Questioning the functioning of the relationship between the aforementioned entrances and competences can precisely constitute the task of a philosophical investigation of intersubjectivity. This investigation will maintain an affinity with the transcendental analysis of the lifeworld in order to define itself as philosophical, but it will at the same time spread through the whole complex of disciplines gathered together under the title of Humanities, and will therefore coincide, at least in part, with an analysis thoroughly anthropological in character.

The question is whether such an anthropologically oriented philosophy still maintains a relationship with the phenomenological project. By thematizing the lifeworld as an object we can describe and analyse, that is, as an object we can experience, the phenomenologist is not claiming to be able to put herself in a position that is external with respect to the lifeworld itself, as the latter is a totality that encompasses both the evidences presupposed by the subjects who act within the natural or the scientific attitude, and the phenomenologist's self-positioning that makes the coming-to-light of the lifeworld possible. A phenomenological analysis of the lifeworld is simply the result of a different way of looking at the lifeworld, a way that posits it as the ground [Boden] for all what is presupposed by any subject that looks at the world from a point of view different from the phenomenological 
one. We can adopt this solution because we have already stated that the lifeworld can emerge and become visible only if the phenomenologist's glance performs its emergence and its visibility. Should Husserl have formulated two different concepts, one for the lifeworld meant as the totality that encompasses both the subjects who experience the world and their reflection upon the world, and another one for the lifeworld meant as the ground of all validity $?^{20}$ If we answer in the affirmative, we run the risk of missing the productive character of the paradox enunciated by Husserl, namely the paradox of a twofold lifeworld, which splits up in order to make possible for the subject to reflect upon that totality in which it still remains included. And the productivity of this paradox can be shown precisely in the moment in which we deal with the necessity to submit the lifeworld to analysis.

Husserl himself can figure out the analysis we are talking about only in the form of an anthropological analysis. As is to be expected, he makes enormous efforts to avoid drawing all the consequences implied by such an analysis. However, it is not without significance that he speaks of invariants in order to define the object of this analysis. These invariants should constitute the object of investigation of an a priori anthropology, which is to be understood as an ontology of the world as well (Hua XXXIX 2008, 57). Without this a priori anthropology the various ways of sensemaking, differing from each other both historically and geographically could not be perceived as variations of the same world. The world that is supposed to remain the same is the world we are familiar with, it is the world that, thanks to its own presence and consistence shapes our habits, or, better, makes the emergence of habits possible. Now, the fact that the never changing structure of the world is strictly interwoven with the possibility for human habits to change both from time to time, and from region to region seems to be the presupposition Husserl needs to state the identity of an ontology of the world with an a priori anthropology. When he asks which is the main characteristic of mankind, that is, which is the peculiarity all human beings must share in order to understand themselves as human beings, the answer is: their historicity (Hua XXXIX 2008, 344). No reader of the Krisis will be surprised by this answer. What could be-if not surprising, perhaps a little disturbing-is the way Husserl depicts this historicity. What Husserl points at, in fact, is the rootedness of each individual in its community, where it was born, has acquired acquaintance with the world, and has gained the opportunity to turn the world itself into the mute horizon both of human experience in general, and of its own experience in particular. The same holds for human groups, no matter whether their dimension is small or big as in the case of a nation. Historicity, in this case, means to be rooted in a country that allows a strong form of identification - a country, therefore, which can be understood in terms of homeland. It is in our homeland that the world becomes familiar to us. In fact, there would be no familiarity with the world without that form of acquaintance with shared values and shared forms of life we can gain only when we participate in the common work that is necessary to guarantee the prosecution of the tradition we belong to. Thus, historicity coincides ${ }^{20}$ The problems concerning the plurivocity of Husserl's notion of life-world are discussed in
Claesges (1972). 
with the persistence of a generative tradition, with the power possessed by a tradition to live on, to reproduce itself and overwhelm the opposite power of time to destroy the traces human beings have left on the earth. Following this train of thought, we can find in the third appendix of the Krisis, namely in the text Fink titled The Origin of Geometry, a historicity that coincides with the capability to leave traces, whereas the vitality of a tradition consists of the capability to institutionalize the way in which these traces are both reproduced and interpreted (Hua VI 1954, 371).

The argumentative strategy Husserl adopts to describe the connection between the rootedness in a Heimat and the historicity that marks the essence of mankind could recall the similar tones we find in Heidegger's commentaries of Hölderlin's hymns "Germanien" and "Der Rhein." 21 But it would be misleading to follow the superficial resemblance of tones, even if the temptation to do so could seem appealing (especially if we consider that the text where Husserl speaks of human historicity is more or less coeval with Heidegger's lecture courses). Notwithstanding his insisting on the völkisch dimension that is taken for characteristic of any human rootedness in a country, Husserl is able to draw a connection between the feeling of belonging to one country and the human capability to cross boundaries and to perceive the whole of humanity as an extension of our homeland: even if the way I perceive the world is biased by the manner in which the human group I belong to has always perceived it, nevertheless what I perceive is the same world I share with the rest of humanity. Precisely the possibility to turn back to the unique world, meant as the source of all objectivity, allows me also to perceive the unity encompassing all different cultural traditions (Hua XXXIX 2008, 340). In this sense, we must recognize how deep Husserl's commitment to the tradition of the Enlightenment was, a statement that does not apply to Heidegger's philosophical position. At the same time, we must recognize how strong, even in Husserl's case, has been the temptation, which never ceased to haunt the European tradition of the Enlightenment, to identify the history of Europe with the most successful example of a unitary cultural tradition, which would have revealed itself capable of overwhelming its own internal differences (Hua XXXIX 2008, 349). ${ }^{22}$

Now, regardless the rhetoric of 'belonging' that affects Husserl's description of human historicity, what must be underlined here is the fact that Husserl's late reflections are able to provide a convincing account of the reason why historicity is to be considered as the ultimate horizon of human experience. ${ }^{23}$ Above all, it must

\footnotetext{
${ }^{21}$ Heidegger (1999).

${ }^{22}$ Derrida (1991).

${ }^{23}$ It is worth taking notice that historicity, according to Husserl, constitutes even the ultimate horizon of animal life in general. If the way a subject can experience historicity depends on its rootedness in a territory, then an experience of the world that can be defined as historical cannot be denied with respect to animals. However, animals are not able to generate a tradition, which remains a peculiarity of human beings. On the other hand, the source of the human capability to generate a tradition, that is, to make sense of the experience of the world we all share as human beings, is deeply rooted in a biologically based characteristic, namely in the fact that we can produce signs by using the expressive potential of our corporeality (Hua XXXIX 2008, 344-346). Even if confined to a footnote, this clue of how complex Husserl's analysis of historicity is seems to me no less important than the main objective I want to pursue within the present essay.
} 
be stressed that the horizon that is at stake here is to be referred not only to the human Umwelt, namely to all that surrounds human experience in both geographical and cultural terms (belonging to a territory, speaking a language, sharing a given set of historically determined values, and so on). If it were so, nothing but the empirical dimension of our being rooted in the world would be affected by historicity. Husserl seems also to be tempted to confer a historical character even to the transcendental dimension that makes possible both the emergence and the formation of objectivity. Indeed, he claims that every act of knowledge, every form of knowledge, every formation bearing in itself the result of an act of knowledge (Gebilde is the expression used by Husserl) is motivated. This means that knowledge, not differently from any other human activity, is part of a tradition, or, which is the same, is rooted in the unity of human history. Husserl makes this statement in a context introduced by a question concerning the absence of presuppositions that is supposed to characterise knowledge (Hua XXIX 1993, 343). It is a common-sense statement that the absence of presuppositions is precisely the main characteristic of any scientific undertaking. But here we are taught not only that knowledge does not occur in absence of presuppositions, but also that its own historicity is precisely that which knowledge presupposes at a deepest level. Husserl goes on with his argument as follows. Acts that confer a meaning on an object, and do so in a way that raises this meaning to the level of universal validity, cannot be detached from the historical horizon to which they belong, nor from the objects the validity of which they attempt to establish. Notwithstanding its being generated within the horizon of history, this established validity of objects does not cease to inform the complex of scientific knowledge. If we operate at the level of the latter, as scientists or so, we can be forgetful of the historical process that generated it. But if we continue to adhere to the phenomenological way of looking at scientific knowledge, we cannot overlook the dependence of acts conferring objectivity upon the broader context of intersubjectivity. Thus, the objectivity possessed by the objects of the lifeworld is thoroughly historical (Hua XXIX 1993, 347f).

Some important consequences can be drawn from the relationship between historicity and the self-positioning of phenomenology as a science of the lifeworld. On the one hand, phenomenology can turn itself into an ontology of the lifeworld —or, an a priori anthropology - without losing its transcendental character only if the task of this ontology consists of an investigation of the invariants that mark the human being in the world. Yet, if the main invariant, to which all other invariants are to be traced back, is historicity, then there is no place at all for an investigation that is supposed to differ essentially from the one carried out by Humanities. If we consider the research project that informs the humanities in general, we potentially gain a complete description of the different ways of inhabiting the world, a description that includes even those invariants that are to be found within every cultural tradition. This description may be a finite one at a given moment of its own internal development, but it is virtually infinite in the sense that the horizon within which it takes place is precisely the infinite horizon of human history. On the other hand, in the present context an important role is played by the relationship investigated by phenomenology between the realm of logical forms and the extent to which they suspend their peculiar onmitemporality 
to become part of the structure of meaning the subject needs in order to build up a coherent and consistent account of the world. If this relationship forms one of the most important issues of phenomenological investigation (if not the most important one), and if the result of this investigation, as we have seen above, brings us to acknowledge the insurmountable historicity of those processes that lead to the formation and establishment of objectivity, then it turns out to be inevitable to suppress any difference between phenomenology and a critical epistemology. The aim of the latter is precisely to make evident which historical, cultural, and political biases must be taken into consideration to explain the emergence and the sedimentation of any form of knowledge. ${ }^{24}$

Are the consequences just drawn above a strained interpretation of some isolated passages of Husserl's late reflection? Probably not, however, if we want to be consistent with respect to the main goal we are pursuing here, namely to explore the possibility of a postfoundational phenomenology, what we are concerned with should not be biased by this question. The interconnection between the empirical and the transcendental subject, which goes through Husserl's reflection on the lifeworld (Hua VI 1954, 190, 214, 268), is the point of departure we need to justify our attempt at moving from a 'pure' phenomenology to a phenomenologicallyoriented stance that understands itself as a discourse that cannot be detached from the field occupied by the Humanities. The transcendental subject is the last instance to which the process of foundation must terminate; the final result of the latter is the discovery that every sense-formation [Sinnbildung] depends on intersubjectivity, and this is the reason why Husserl insists on emphasizing the fact that even the objectivity that characterizes scientific knowledge is subject-relative. A part of this discovery is the historical nature of the problems discussed by phenomenology as a science of the lifeworld (Hua VI 1954, 378). Husserl was surely close to claiming that only by taking seriously the historicity of the lifeworld itself would it have been possible to achieve the final scope promised by a radical phenomenological foundation. What he was not ready to recognize, however, was that this radical foundation should have been understood in terms of a thorough historicisation of subjectivity as well. ${ }^{25}$ As a clue of the resistance offered by Husserl against this historicisation, we should look at the way in which he speaks, in some passages, of the invariants that are also constitutive of human experience of the world. Differently from the above quoted passages where the anthropological nature of these invariants has been stated very clearly, Husserl tries sometimes to define these invariants in opposition to what could be the result of the efforts made by a historian in order to

\footnotetext{
${ }^{24} \mathrm{~A}$ good example of what could be understood as a sound and convincing accomplishment of a critical epistemology can be found in Foucault's work (especially in Foucault 1972, where the interweaving of empirical and transcendental within the production of scientific discursivity has been made explicit as an object of investigation). It is also worth mentioning the relationship between Foucault's philosophy and the way in which Cavaillès took up and modified Husserlian phenomenology: in doing so, Cavaillès prepared the ground necessary to every further development along the path we are suggesting here (see Cavaillès 1947).
}

${ }^{25}$ Ströker (1993), 165-205. 
describe the process of sense-sedimentation [Sinnsedimentierung]. Husserl gives indeed the impression that it is always possible to distinguish the empirical work of the historian from a transcendental analysis of the invariant structures of the historical world. The meaning of these structures could be caught and perceived with evidence thanks to a reflection on the historical material the aim of which is to purify it from its empirical character (Hua XXIX 1993, 241). Once again, the obsession with 'purity' seems to be Husserl's main concern.

However, for the argument we are putting forth here it is above all worth drawing our attention to how Husserl understands the method we need to attain the knowledge of the invariants that underlie any form of given experience of the world. Husserl simply refers to the already well-functioning method of free variation. The method has been available within phenomenology for a long time and has been applied whenever the old question of the universal needed to undergo a phenomenological investigation. As in the previous cases, Husserl attempts to preserve the purity of the essence attained thanks to the free variation; further, he does not seem to deviate from the conviction that the pure essence of the singular object starting from which the variation begins is nothing but what the object has always included as a constitutive part of its own object-like character. On one hand, we could reproach Husserl for having not discussed the difference (if any) between the free variation and the classical method of induction. On the other hand, we could observe that the method is caught in a vicious circle, in the sense that certain knowledge of the universal is already presupposed whenever we choose a given singular object and decide to 'extract' the essence it contains by applying the method of free variation. At any rate, we cannot really address here the objections the method of free variation could easily undergo. In order to do this, we should engage in a deeper discussion of the whole issue. In the present context, the only thing we should not overlook is the coincidence between the phenomenological method of free variation and the comparison between similar states of affairs that can be found within the praxis of the Humanities. The world that surrounds me refers to an infinite horizon that includes both events and processes that occurred in the past, and events and processes that are taking place now elsewhere. At the same time, I also know that it is always possible to refer to the general structure of the lifeworld (Hua VI 1954, 142). The latter, as we have seen above, makes both the cultural and the historical crossing possible. What I perceive along with those crossings can be recorded, measured, tested, analysed, accounted for: in other words, scientific knowledge of both historical and cultural differences is possible. The epistemic basis for any scientific recording of and accounting for cultural and historical data is given by my capability to put forth a continuum that begins with the already-known and moves to the unknown all the possible forms of historical existence. Husserl claims that this modalisation of my own horizon is not completely free, in the sense that it is still subdued to the spatial and temporal biases that make up every human experience of the world (Hua XXIX 1993, 63-65). We can easily agree with this claim without evoking once again the aforementioned difficulties related to the method of free variation. But there is a further step to be taken, namely to notice that a methodology based 
on the progressive extension of horizons has been constituting the core of any form of scientific knowledge since the humanities began to reflect on their own epistemic status.

A clear awareness of this issue can be found in the discussion about the reliability of our historical sources concerning ancient Rome. This discussion, which took place during the first part of the eighteenth century, came before the establishment of a self-confident historical discipline, but it is worth mentioning because it clearly shows that the historical consciousness, once raised, bears with itself the necessity to cope with questions of methodological nature. Some decades later, at the beginning of the nineteenth century, on German soil, which has been understood as the cradle of a rigorous philology since that moment, we encounter a Friedrich August Wolf, who was able to state very clearly the hypothetical nature of all assertions made within the historical reconstruction of the past - a hypothetical nature that does not imply a diminished rigour. But it is due to August Boeckh if we can better grasp the fact that any historical knowledge rests on the possibility to modify our own horizon until we reach a sound understanding of what makes up the peculiarity of other cultures and other historical ages. "Erkenntnis des Erkannten" ("knowing of the known") was the formula uttered by Boeckh in order to make clear the necessary relationship between the point of departure of scientific knowledge, that is, the living horizon within which I act as a subject, and the alien world that must be submitted to investigation. Not different from the modalisation of the horizon within which the subject of knowledge operates is the procedure adopted by the anthropologist. The anthropological discipline, born officially in the second part of the nineteenth century, is in fact based on a method that can be seen as an application of the philologist's method in a field where we cannot rely on written sources as far as the access to otherness is concerned.

The examples that could be mentioned here are innumerable - and if I do not go into details, it is not because the length of the present contribution would not allow it: more simply, it is the whole history of the Humanities during the modern age that should be taken into consideration here. ${ }^{26}$ But the point that deserves our attention remains the aforementioned similarity between the methodology suggested by Husserl in order to capture the invariants of the lifeworld and the method effectively applied within the Humanities in order to achieve the necessary acquaintance with alien forms of life.

The last-and conclusive-point of our investigation concerns the question whether an autonomous place for a philosophical questioning can be maintained. The proposed postfoundational phenomenology could be read as a suggestion to merge any philosophical inquiry with the encyclopaedia of the Humanities. But there is a specific function that is still to be accomplished by philosophy.

\footnotetext{
${ }^{26}$ In Leghissa (2007), there is a more detailed account of the epistemic structure of the Humanities with special reference to classical philology, which has been the first discipline among the Humanities to develop the methodological awareness we are dealing with here.
} 
As Husserl knew very well, scientific disciplines do not always bind together the theory they attempt to shape of a specific field with the epistemology the same theory rests on (Hua XVII 1974, 8, 32). To elucidate the various forms taken by the relation between the two would be precisely the task of a phenomenologically-oriented philosophy. Such a task would not coincide with a 'transcendental foundation' of the sciences of the lifeworld, as the phenomenologist's glance is entirely internal to the level where the description of the lifeworld takes place. It would rather mean to turn the phenomenological attitude from a 'reflection above' the validity of the world into a 'reflection within' the historical processes that inform the intesubjective constitution of the world. Put in this way, we can bestow a new meaning on Husserl's seemingly obscure remarks on the einströmen. Under this notion, which is present both in the Krisis (Hua VI 1954, 115, 213) and in the related texts (Hua XXIX 1993, 77-83), Husserl referred to the fact that phenomenology, as well as any other form of theory that brings in itself the awareness of the subjective-relative character of knowledge, 'flows into' the lifeworld it reflects on. Such a 'flowing into,' or einströmen, can be well understood as the form phenomenology assumes in the moment in which it decides to accompany the efforts made by human beings when they keep the world at a distance in order to gain a critical attitude towards it. Not different from other forms of critical theory, but perhaps better equipped than they are as far the exercise of distantiation is concerned, phenomenology can then present itself as a praxis, more precisely as that specific form of exercise that is required whenever we have to deal with the paradox generated by the intersubjective constitution of the world.

\section{References}

References to Husserl's works are enclosed in parentheses (round brackets) and embedded in the text. First comes "Hua," which is the abbreviation of the German Complete Edition (Husserliana-Gesammelte Werke), and then the volume number followed by the page number.

Hua VI. 1954. Die Krisis der europäischen Wissenschaften und die transzendentale Phänomenologie. Herausgegeben vonW. Biemel. Den Haag: Nijhoff.

Hua VII. 1959a. Erste Philosophie (1923-1924). 1. Kritische Ideengeschichte. Herausgegeben von R. Boehm. Den Haag: Nijhoff.

Hua VIII. 1959b. Erste Philosophie (1923-1924). 2. Theorie der phänomenologischen Reduktion. Herausgegeben von R. Boehm. Den Haag: Nijhoff.

Hua XI. 1966. Analysen zur passiven Synthesis: Aus Vorlesungs- und Forschungsmanuskripten, 1918-1926. Herausgegeben von M. Fleischer. Den Haag: Nijhoff.

Hua XVII. 1974. Formale und transzendentale Logik: Versuch einer Kritik der logischen Vernunft. Herausgegeben von P. Janssen. Den Haag: Nijhoff.

Hua XXIX. 1993. Die Krisis der europäischen Wissenschaften und die transzendentale Phänomenologie. Ergänzungsband. Texte aus dem Nachlass 1934-1937. Herausgegeben von R.N. Smid. Dordrecht-Boston-London: Kluwer.

Hua XXXIX. 2008. Die Lebenswelt. Auslegungen der vorgegebenen Welt und ihrer Konstitution. Texte aus dem Nachlass (1916-1937). Herausgegeben von R. Howa. Dordrecht: Springer. 


\section{Further Literature}

Bloor, D. 1976. Knowledge and social imagery. Chicago: The University of Chicago Press.

Blumenberg, H. 2006. Beschreibung des Menschen. Aus dem Nachlaß herausgegeben von M. Sommer. Frankfurt am Main: Suhkamp.

Blumenberg, H. 2010. Theorie der Lebenswelt. Frankfurt am Main: Suhrkamp.

Bourdieu, P. 1977. Outline of a theory of practice. Cambridge: Cambridge University Press.

Bourdieu, P. 2001. Science de la science et reflexivité. Paris: Editions Raison d'agir.

Carr, D. 1974. Phenomenology and the problem of history: A study of Husserl's transcendental philosophy. Evanston: Northwestern University Press.

Cavaillès, J. 1947. Sur la logique et la théorie de la science. Paris: Presses Universitaire de France.

Claesges, U. 1972. Zweideutigkeiten in Husserls Lebenswelt-Begriff. In Perspektiven transzendentalphänomenologischer Forschung, eds. U. Claesges and K. Held, 85-101. Den Haag: Nijhoff.

Derrida, J. 1991. L'autre cap, suivi de la démocratie ajournée. Paris: Minuit.

Dodd, J. 2004. Crisis and reflection. An essay on Husserl's crisis of the European sciences. Dordrecht: Kluwer.

Drummond, J.J. 1990. Husserlian intentionality and non-foundational realism. Dordrecht: Kluwer.

Fleck, L. 1979. In Genesis and development of a scientific fact, eds. Trenn, T.J. and R.K. Merton. Chicago/London: The University of Chicago Press.

Foucault, M. 1972. The Archeology of Knowledge. Trans. A.M. Sheridan Smith. New York: Pantheon Books.

Grathoff, R. 1989. Milieu und Lebenswelt. Einführung in die phänomenologische Soziologie und die sozial-phänomenologische Forschung. Frankfurt am Main: Suhrkamp.

Hacking, I. 1992. The self-vindication of the laboratory sciences. In Science as practice and culture, ed. A. Pickering, 29-64. Chicago/London: The University of Chicago Press.

Heidegger, M. 1999. In Hölderlins Hymnen "Germanien" und "Der Rhein" (Wintersemester 1934/35), ed. S. Ziegler, (GA Bd. 39). Frankfurt am Main: Klostermann.

Held, K. 1991. Husserls neue Einführung in die Philosophie: der Begriff der Lebenswelt. In Lebenswelt und Wissenschaft. Studien zum Verhältnis von Phänomenologie und Wissenschaftstheorie, ed. C.F. Gethmann, 79-113. Bonn: Bouvier.

Kisiel, T.J. 1970. Phenomenology as the science of science. In Phenomenology and the natural sciences, eds. J.J. Kockelmans and T.J. Kisiel, 5-44. Evanston: Northwestern University Press.

Landgrebe, L. 1963. Der Weg der Phänomenologie. Gütersloh: Mohn.

Landgrebe, L. 1968. Phänomenologie und Geschichte. Gütersloh: Mohn.

Landgrebe, L. 1982. Faktizität und Individuation. Studien zu den Grundfragen der Phänomenologie. Hamburg: Meiner.

Leghissa, L. 2007. Incorporare l'antico. Filologia classica e invenzione della modernità. Milan: Mimesis.

Luhmann, N. 1995. Social systems. Stanford: Stanford University Press.

Mensch, J.R. 2001. Postfoundational phenomenology: Husserlian reflection on presence and embodiment. University Park: Pennsilvania State University Press.

Mohanty, J.N. 1982. Husserl and Frege. Bloomington: Indiana University Press.

Ricoeur, P. 1949. Husserl et le sens de l'histoire. In Revue de Métaphysique et de Morale 54: 280-316. Now in Ricoeur. 2004. A l'école de la phénoménologie, 19-64. Paris: Vrin.

Ströker, E. 1987. Phänomenologische Studien. Frankfurt am Main: Klostermann.

Ströker, E. 1993. Husserl's transcendental phenomenology. Stanford: Stanford University Press.

Willard, D. 1984. Logic and the objectivity of knowledge. A study in Husserl's early philosophy. Athens: Ohio University Press.

Winch, P. 1958. The idea of a social science. London: Routledge \& Kegan Paul.

Zahavi, D. 2003. Husserl's phenomenology, 79-140. Stanford: Stanford University Press. 